\title{
Urine Cystatin C as a Biomarker of Proximal Tubular Function Immediately after Kidney Transplantation
}

\author{
Isaac E. Hall ${ }^{a}$ Jay L. Koyner ${ }^{b}$ Mona D. Doshi ${ }^{c} \quad$ Richard J. Marcus $^{d}$ \\ Chirag R. Parikh ${ }^{a}$

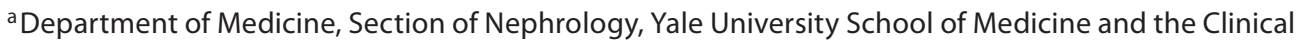 \\ Epidemiology Research Center, VAMC, New Haven, Conn., ${ }^{b}$ Department of Medicine, Pritzker School of Medicine \\ University of Chicago, Chicago, III., 'Department of Medicine, Division of Nephrology, Wayne State University \\ School of Medicine, Detroit, Mich., and d Department of Medicine, Division of Nephrology and Hypertension, \\ Allegheny General Hospital, Drexel University College of Medicine, Pittsburgh, Pa., USA
}

\section{Key Words}

Transplantation • Biomarkers • Ischemia/reperfusion • Outcomes

\begin{abstract}
Background/Aims: Clinical methods to predict allograft function soon after kidney transplantation are ineffective. Methods: We analyzed urine cystatin C (CyC) in a prospective multicenter observational cohort study of deceaseddonor kidney transplants to determine its peritransplant excretion pattern, utility for predicting delayed graft function (DGF) and association with 3-month graft function. Serial urine samples were collected for 2 days following transplant and analyzed blindly for CyC. We defined DGF as any hemodialysis in the first week after transplant, slow graft function (SGF) as a serum creatinine reduction $<70 \%$ by the first week and immediate graft function (IGF) as a reduction $\geq 70 \%$. $\boldsymbol{R} \boldsymbol{e}$ sults: Of 91 recipients, 33 had DGF, 34 had SGF and 24 had IGF. Urine CyC/urine creatinine was highest in DGF for all time-points. The area under the curve $(95 \% \mathrm{CI})$ for predicting DGF at 6 h was 0.69 (0.57-0.81) for urine $C y C, 0.74$ (0.62-0.86) for urine $\mathrm{CyC} /$ urine creatinine and 0.60 (0.45-0.75) for percent change in urine $\mathrm{CyC}$. On the first postoperative day,
\end{abstract}

urine $\mathrm{CyC} /$ urine creatinine and percent change in urine $\mathrm{CyC}$ were associated with 3-month graft function. Conclusion: Urine CyC on the day after transplant differs between degrees of perioperative graft function and modestly corresponds with 3-month function.

Copyright $\odot 2011$ S. Karger AG, Basel

\section{Introduction}

The scarcity of transplantable kidneys indicates the need for appropriate diagnostic tools. Early determination of allograft function and prognosis could lead to the development of therapies for kidneys with significant ischemia-reperfusion injury (IRI) and more effective recipient management, thereby improving outcomes. Unfortunately, the use of baseline characteristics alone (donor and recipient age, etc.) has limited accuracy in predicting outcomes. Recent insights regarding IRI biomarkers in the setting of acute kidney injury (AKI) suggest allograft injury and recovery could be better characterized by these biomarkers [1].

Severe IRI in deceased-donor kidney transplants results in delayed graft function (DGF), which occurs in

\section{KARGER}

(C) 2011 S. Karger AG, Basel

Fax +41613061234

E-Mail karger@karger.ch

www.karger.com
Accessible online at: www.karger.com/ajn
Chirag Parikh, MD, $\mathrm{PhD}$

Section of Nephrology, Yale University and VAMC

950 Campbell Ave, Mail Code 151B, Bldg 35 A, Room 219

West Haven, CT 06516 (USA)

Tel. +1 203932 5711, ext. 4300, E-Mail Chirag.Parikh@ Yale.edu 
approximately one third of recipients $[2,3]$. While DGF is typically defined as hemodialysis in the first week following kidney transplantation, slow graft function (SGF) has been defined by various serum creatinine $(\mathrm{Cr})$ cutoff values during the first several days of transplant $[4,5]$. Compared with immediate graft function (IGF), however, both diagnoses are associated with worse long-term outcomes $[2,5,6]$.

Researchers have discussed replacing serum $\mathrm{Cr}$ in clinical practice with serum cystatin $\mathrm{C}(\mathrm{CyC})$ for years. $\mathrm{CyC}$ is a $13.4-\mathrm{kDa}$ cysteine protease inhibitor produced in all nucleated cells. It is released into the circulation at a constant rate, freely filtered by glomeruli, taken up by proximal tubular cells for degradation (without return to the circulation) and undergoes no tubular secretion. Studies have described the superiority of serum CyC over serum $\mathrm{Cr}$ for diagnosing filtration failure in the setting of AKI $[7,8]$. In health, the amount of detectable urinary CyC is low $(<0.28 \mathrm{mg} / \mathrm{l})$ because of effective proximal tubular reabsorption/degradation of this low-molecularweight protein and is unrelated to characteristics like gender and age [9]. Urine $\mathrm{CyC}$ concentrations increase with AKI due to decreased reabsorption from injured/ dysfunctional tubules. As such, urine $\mathrm{CyC}$ can be considered a marker of proximal tubular function and has been described as an effective urinary AKI biomarker in adults following cardiac surgery and admission to medical/surgical intensive care [10-12]. No study, however, has reported urine $\mathrm{CyC}$ excretion patterns immediately following kidney transplantation or described its utility for detecting/predicting allograft function in the peritransplant setting.

We recently demonstrated that urinary neutrophil gelatinase-associated lipocalin and IL-18 within the first $24 \mathrm{~h}$ following transplant predict DGF better than changes in serum $\mathrm{Cr}$ and correlate with 3-month allograft function in a multicenter prospective-cohort study of nonpreemptive deceased-donor kidney transplants [1]. Utilizing this cohort, our primary goal for the current study was to describe urine $\mathrm{CyC}$ excretion patterns immediately following transplant in recipients with DGF, SGF and IGF. In addition, we sought to determine the degree of association between peritransplant urine $\mathrm{CyC}$ levels and 3-month allograft function.

\section{Methods}

The institutional review boards from all centers approved this study. See our previous publication for detailed methods regarding subject recruitment and care, exclusion criteria, outcome def- initions, and sample collection/processing [1]. In brief, we collected the first sample ( $0 \mathrm{~h}$ time-point) upon transfer to the postanesthesia unit, typically within $1 \mathrm{~h}$ of surgery. We defined DGF as at least one post-transplant hemodialysis in the first week. In those without DGF, we defined SGF as a reduction in serum $\mathrm{Cr}$ by $<70 \%$ on day 7 and IGF as $\geq 70 \%$ [5]. Laboratory personnel, who were blinded to patient information, measured urine $\mathrm{CyC}$ by particle-enhanced nephelometric immunoassay using a Behring nephelometer [13]. Intra- and interassay variability were $<5 \%$. The ratio of urine $\mathrm{CyC} /$ urine $\mathrm{Cr}$ was calculated individually for each subject. Percent change in urine $\mathrm{CyC}$ was calculated individually for each subject as $100 \times[$ (time-point of interest $-0 \mathrm{~h}$ time-point) $\div 0 \mathrm{~h}$ time-point]. Glomerular filtration rate (GFR) was estimated by the Modified Diet in Renal Disease equation [14].

\section{Statistics}

We used ANOVA and Kruskal-Wallis tests to compare continuous values between recipients with DGF, SGF and IGF. We used Fisher's exact tests to compare categorical values between groups. To compare 3-month allograft function between medians of urine CyC, we used Student's t and Mann-Whitney U tests. A two-tailed $\alpha$ of 0.05 was considered significant. We also performed receiver-operating characteristic (ROC) curve analysis to determine the accuracy of urine $\mathrm{CyC}$ at each time-point for predicting DGF. We carried out all analyses using SAS 9.2 for Windows (SAS Institute, Cary, N.C., USA).

\section{Results}

\section{Study Cohort}

Characteristics and outcomes for the 91 recipients are listed in table 1 . DGF occurred in 33 patients, 34 had SGF and 24 had IGF. The only significant differences in characteristics between groups were donor status and duration of dialysis prior to transplant. There were no acute rejections in the first week, but 11 developed rejection by the 3-month follow-up. One patient (in the DGF group) had both returned to dialysis and died within 3 months.

\section{Early Function}

Urine $\mathrm{CyC}$ values were highest for DGF (fig. 1). Urine CyC/urine Cr values for DGF were statistically different from SGF and IGF at all time-points. Percent change in urine $\mathrm{CyC}$ demonstrated consistent increases from levels obtained at $0 \mathrm{~h}$ for those with DGF, while those with IGF had consistent decreases (fig. 2). For SGF, percent change in urine $\mathrm{CyC}$ increased during the day of transplant with minimal change on the first postoperative day (POD), and it was not until the second POD that values substantially decreased from $0 \mathrm{~h}$ values. 
Table 1. Summary of kidney transplant donor and recipient characteristics and outcomes by graft function

\begin{tabular}{|c|c|c|c|c|c|c|}
\hline & & All $(n=91)$ & DGF $(n=33)$ & SGF $(\mathrm{n}=34)$ & $\operatorname{IGF}(\mathrm{n}=24)$ & $\mathrm{p}$ value \\
\hline \multirow{14}{*}{$\begin{array}{l}\text { Donor } \\
\text { characteristics }\end{array}$} & Age & $37.2 \pm 17.0$ & $33.5 \pm 17.1$ & $39.5 \pm 16.5$ & $39.0 \pm 17.6$ & \\
\hline & Male & $56(62)$ & $19(58)$ & $20(59)$ & $17(71)$ & \\
\hline & BMI & $27.9 \pm 6.1$ & $27.4 \pm 7.3$ & $28.4 \pm 5.5$ & $28.0 \pm 5.3$ & \\
\hline & \multicolumn{6}{|l|}{ Race } \\
\hline & Black & $12(13)$ & $3(9)$ & $6(18)$ & $3(13)$ & \\
\hline & Caucasian & $71(78)$ & $29(88)$ & $24(73)$ & $18(78)$ & \\
\hline & Hypertension & $28(31)$ & $8(24)$ & $12(35)$ & $8(33)$ & \\
\hline & Diabetes & $8(9)$ & $1(3)$ & $5(15)$ & $22(92)$ & \\
\hline & \multicolumn{6}{|l|}{ Cause of death } \\
\hline & Head trauma & $35(38)$ & $14(42)$ & $12(35)$ & $9(38)$ & \\
\hline & Stroke & $35(38)$ & $9(27)$ & $15(44)$ & $11(46)$ & \\
\hline & Anoxia & $12(13)$ & $6(18)$ & $5(15)$ & $1(4)$ & \\
\hline & ECD & $16(18)$ & $2(6)$ & $7(21)$ & $7(29)$ & 0.05 \\
\hline & DCD & $8(9)$ & $7(21)$ & $1(3)$ & 0 & 0.007 \\
\hline Recipient & Age & $51.6 \pm 11.9$ & $48.6 \pm 11.1$ & $53.4 \pm 11.5$ & $53.0 \pm 13.1$ & \\
\hline \multirow[t]{26}{*}{ characteristics } & Male & $57(63)$ & $22(67)$ & $18(53)$ & $17(71)$ & \\
\hline & BMI & $29.5 \pm 6.7$ & $30.7 \pm 7.9$ & $29.2 \pm 5.8$ & $28.3 \pm 6.4$ & \\
\hline & \multicolumn{6}{|l|}{ Race } \\
\hline & Black & $52(57)$ & $22(67)$ & $17(50)$ & $13(54)$ & \\
\hline & Caucasian & $35(38)$ & $11(33)$ & $16(47)$ & $8(33)$ & \\
\hline & \multicolumn{6}{|l|}{ Dialysis mode } \\
\hline & Peritoneal & $18(20)$ & $3(9)$ & $8(24)$ & $7(29)$ & \\
\hline & Hemodialysis & $73(80)$ & $30(91)$ & $26(76)$ & $17(71)$ & \\
\hline & Hours since last hemodialysis & $25.6 \pm 18.3$ & $28.4 \pm 20.1$ & $24.2 \pm 15.2$ & $22.7 \pm 20.8$ & \\
\hline & Dialysis duration, months & $61.0 \pm 42.9$ & $79.6 \pm 51.5$ & $48.6 \pm 28.8$ & $53.4 \pm 39.4$ & 0.02 \\
\hline & \multicolumn{6}{|l|}{ Cause of ESRD } \\
\hline & Hypertension & $30(33)$ & $10(30)$ & $11(33)$ & $9(38)$ & \\
\hline & Diabetes & $23(26)$ & $8(24)$ & $7(21)$ & $8(33)$ & \\
\hline & Previous transplant & $11(12)$ & $5(15)$ & $3(9)$ & $3(13)$ & \\
\hline & Class I PRA\% & $8.8 \pm 22.4$ & $10.4 \pm 26.4$ & $7.0 \pm 14.7$ & $9.1 \pm 25.7$ & \\
\hline & Class II PRA\% & $5.6 \pm 17.7$ & $7.6 \pm 20.1$ & $1.8 \pm 6.8$ & $8.0 \pm 23.2$ & \\
\hline & Cold ischemia time, $\mathrm{h}$ & $17.3 \pm 10.1$ & $20.3 \pm 12.5$ & $17.4 \pm 9.1$ & $13.2 \pm 6.0$ & \\
\hline & Machine perfusion used & $20(22)$ & $5(15)$ & $8(24)$ & $7(29)$ & \\
\hline & \multicolumn{6}{|l|}{ Induction regimen } \\
\hline & Antithymocyte globulin & $41(45)$ & $20(61)$ & $17(50)$ & $13(54)$ & \\
\hline & Basiliximab/daclizumab & $50(55)$ & $13(39)$ & $17(50)$ & $11(46)$ & \\
\hline & \multicolumn{6}{|l|}{ HLA mismatches } \\
\hline & 0 & $5(5)$ & $1(3)$ & $2(6)$ & $2(8)$ & \\
\hline & $1-5$ & $66(73)$ & $26(79)$ & $24(71)$ & $16(67)$ & \\
\hline & 6 & $20(22)$ & $6(18)$ & $8(24)$ & $6(25)$ & \\
\hline & Any HLA-DR mismatch & $70(88)$ & $24(86)$ & $26(90)$ & $20(87)$ & \\
\hline Recipient & Discharge serum Cr, mg/dl & $4.3 \pm 2.8$ & $6.4 \pm 3.1$ & $3.7 \pm 1.8$ & $2.1 \pm 1.0$ & $<0.0001$ \\
\hline \multirow{9}{*}{ outcomes } & Length of stay, days & $6.9 \pm 2.6$ & $7.6 \pm 3.2$ & $6.6 \pm 2.2$ & $6.4 \pm 2.1$ & \\
\hline & Acute rejection within 3 months & $11(14)$ & $6(23)$ & $3(11)$ & $2(9)$ & \\
\hline & 3-month serum $\mathrm{Cr}, \mathrm{mg} / \mathrm{dl}$ & $1.7 \pm 0.6$ & $1.9 \pm 0.7$ & $1.7 \pm 0.6$ & $1.6 \pm 0.4$ & \\
\hline & $>2$ & $26(29)$ & $10(30)$ & $11(32)$ & $5(21)$ & \\
\hline & 3-month GFR, $\mathrm{ml} / \mathrm{min} / 1.7 \mathrm{~m}^{2}$ & $50.4 \pm 18.6$ & $48.6 \pm 17.7$ & $47.7 \pm 16.3$ & $56.7 \pm 21.9$ & \\
\hline & $<60$ & $68(75)$ & $26(79)$ & $27(79)$ & $15(63)$ & \\
\hline & $<30$ & $10(11)$ & $6(18)$ & $3(9)$ & $1(4)$ & \\
\hline & Return to dialysis within 3 months & $1(1)$ & $1(3)$ & $0(0)$ & $0(0)$ & \\
\hline & Death & $1(1)$ & $1(3)$ & $0(0)$ & $0(0)$ & \\
\hline
\end{tabular}

Continuous values are means $\pm \mathrm{SD}$, counts are $\mathrm{n}(\%)$. ESRD $=$ End-stage renal disease; $\mathrm{ECD}=$ expanded-criteria donor; $\mathrm{DCD}=$ donation after cardiac death; HLA = human leukocyte antigen; PRA = panel reactive antibody. Only significant $\mathrm{p}$ values are shown; calculated between the 3 groups using the Kruskal-Wallis test (continuous values) or Fisher's exact test (categorical values). 


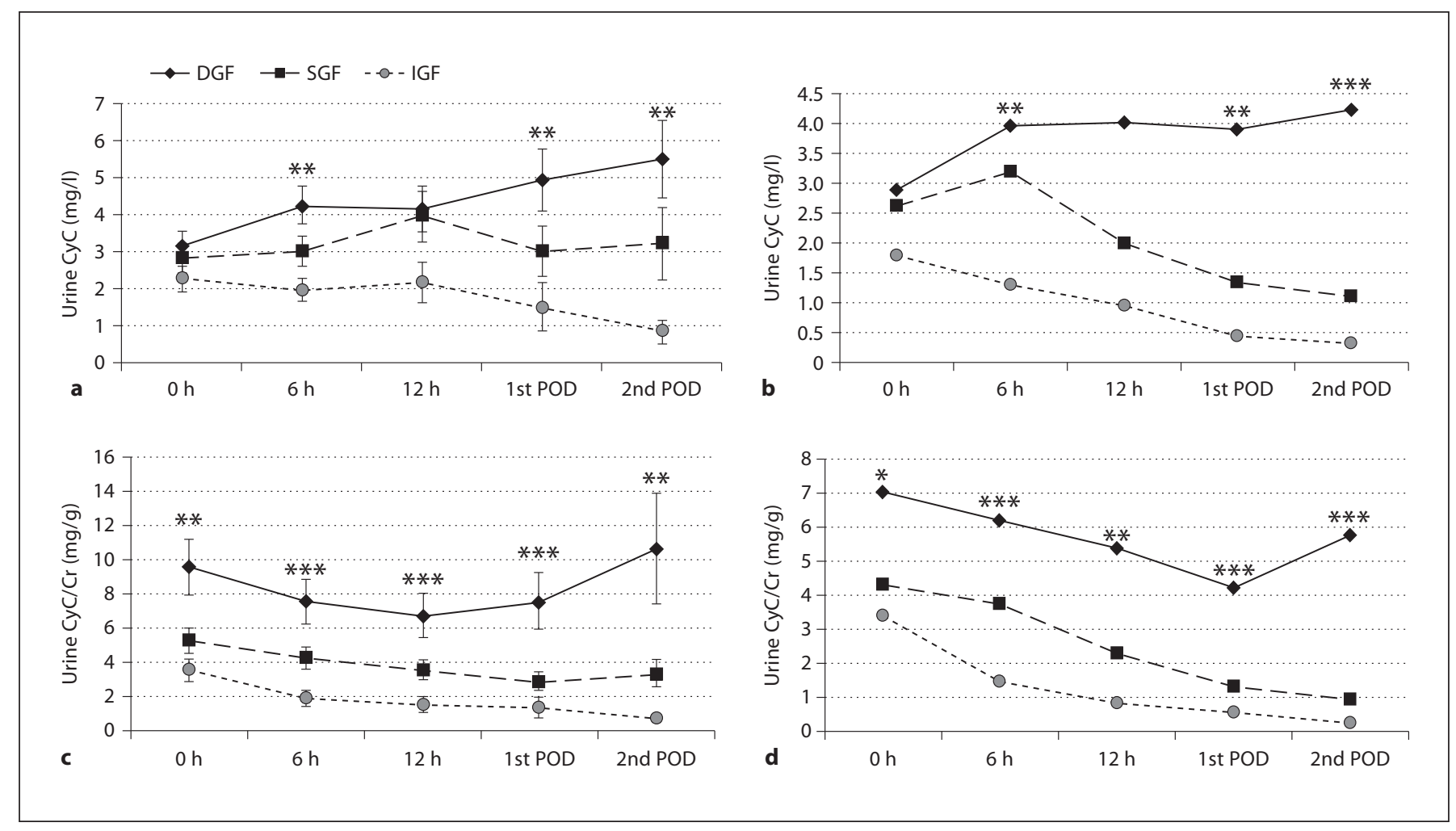

Fig. 1. Mean and median values for urine $\mathrm{CyC}$ and ratio with urine $\mathrm{Cr}$ by graft function after transplant. a Mean urine CyC values (SE bars) by graft function. b Median urine CyC values by graft function. c Mean urine $\mathrm{CyC} /$ urine $\mathrm{Cr}$ with SE by graft function. $\mathbf{d}$ Median urine CyC/urine Cr by graft function. ${ }^{*} \mathrm{p}<0.05,{ }^{* *} \mathrm{p}<0.01$, ${ }^{* * *} \mathrm{p}<0.001$ by ANOVA (means) or Kruskal-Wallis tests (medians).

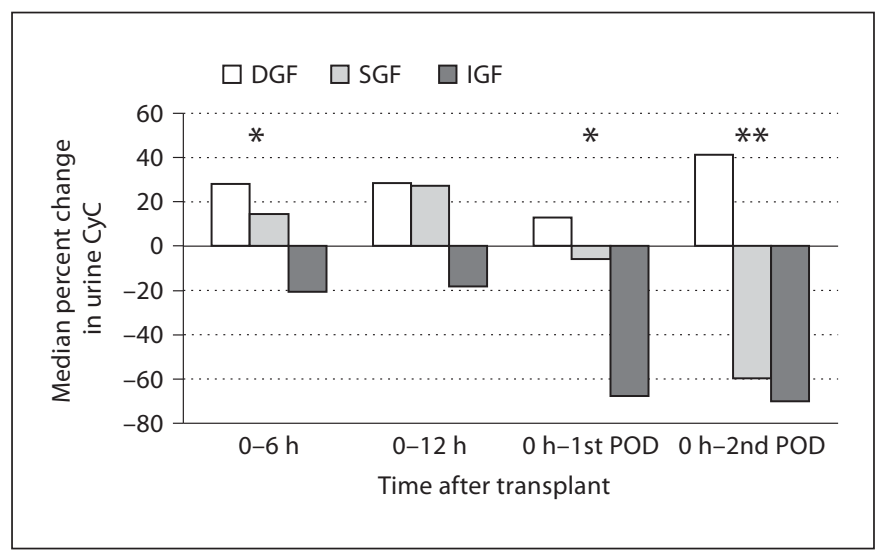

Fig. 2. Proximal tubular function assessed by percent change in urine $\mathrm{CyC}$ after transplant. Percent change calculated for each patient individually, values are medians for the group. ${ }^{*} \mathrm{p}<0.05$, ${ }^{* *} \mathrm{p}<0.01$ by Kruskal-Wallis tests.

\section{ROC Analysis}

ROC curves revealed urine $\mathrm{CyC}$ had moderate utility for predicting DGF with areas under the curve (AUCs) between $0.57-0.74$. AUCs and optimal cutoff values for predicting DGF at $0 \mathrm{~h}, 6 \mathrm{~h}$ and the first POD for urine $\mathrm{CyC}$, urine $\mathrm{CyC} /$ urine $\mathrm{Cr}$ and percent change in urine $\mathrm{CyC}$ are shown in table 2.

\section{Three-Month Function}

Thee-month serum $\mathrm{Cr}$ and GFR varied only slightly by early graft function (table 1). Three-month GFR was not statistically different when separated by medians of urine $\mathrm{CyC}$, urine $\mathrm{CyC} /$ urine $\mathrm{Cr}$ and percent change in urine $\mathrm{CyC}$ before the first POD (table 3 ). Using values on the first POD, however, the 3-month GFR was higher for those with lower values of urine $\mathrm{CyC} / \mathrm{urine} \mathrm{Cr}$ (lower vs. upper median; t test $\mathrm{p}=0.05$, Mann-Whitney $\mathrm{U}$ test $\mathrm{p}=$ 0.07 ) and those with larger decreases in urine $\mathrm{CyC}$ (lower vs. upper median of percent change in urine $\mathrm{CyC} ; \mathrm{p}=$ 0.01 for $t$ test and Mann-Whitney U test). 
Table 2. Cutoff values and accuracy of urine $\mathrm{CyC}$ for predicting DGF at $0 \mathrm{~h}, 6 \mathrm{~h}$ and the first POD after transplant

\begin{tabular}{llllllll}
\hline & Time-point & Cutoff & AUC (95\% CI) & Sensitivity & Specificity & LR+ & LR- \\
\hline Urine CyC, mg/l & 0 h & 3.97 & $0.57(0.44-0.70)$ & 0.34 & 0.82 & 1.95 & 0.80 \\
& 6 h & 3.36 & $0.69(0.57-0.81)$ & 0.67 & 0.64 & 1.86 & 0.52 \\
& 1st POD & 1.92 & $0.69(0.57-0.82)$ & 0.70 & 0.73 & 2.61 & 0.41 \\
\hline Urine CyC/Cr, mg/g & 0 h & 6.55 & $0.69(0.57-0.82)$ & 0.64 & 0.71 & 2.25 & 0.50 \\
& 6 h & 3.90 & $0.74(0.62-0.86)$ & 0.73 & 0.75 & 2.87 & 0.36 \\
& 1st POD & 1.82 & $0.71(0.59-0.83)$ & 0.76 & 0.67 & 2.28 & 0.36 \\
\hline Percent change in urine CyC & 0-6 h & 37.2 & $0.60(0.45-0.75)$ & 0.48 & 0.83 & 2.76 & 0.63 \\
& 0-1st POD & -67.5 & $0.65(0.52-0.77)$ & 0.82 & 0.47 & 1.55 \\
\hline
\end{tabular}

Optimal cutoff values determined by highest sum of sensitivity+specificity.

LR+ = likelihood ratio for a positive test; LR- = likelihood ratio for a negative test.

Table 3. Three-month graft function by biomarkers below vs. above median values at $0 \mathrm{~h}, 6 \mathrm{~h}$ and the first POD after transplant

\begin{tabular}{llll}
\hline & Time-point & $\begin{array}{l}\text { Biomarker } \leq \text { median } \\
\text { mean 3 months GFR } \pm \text { SD }\end{array}$ & $\begin{array}{l}\text { Biomarker median } \\
\text { mean } 3 \text { months GFR } \pm \text { SD }\end{array}$ \\
\hline Urine CyC, mg/l & $0 \mathrm{~h}$ & $48.7 \pm 18.8$ & $50.5 \pm 14.6$ \\
& $6 \mathrm{~h}$ & $49.9 \pm 22.5$ & $52.1 \pm 15.4$ \\
& 1 st POD & $53.4 \pm 21.4$ & $48.4 \pm 15.6$ \\
\hline Urine CyC/Cr, mg/g & $0 \mathrm{~h}$ & $48.5 \pm 18.0$ & $49.9 \pm 15.9$ \\
& $6 \mathrm{~h}$ & $50.9 \pm 21.3$ & $40.4 \pm 17.7$ \\
\hline Percent change in urine CyC & 1st POD & $54.8 \pm 22.1$ & $46.5 \pm 14.5$ \\
\hline Percent change in serum Cr & $0-6 \mathrm{~h}$ & $49.7 \pm 17.5$ & $54.0 \pm 14.9$ \\
\hline
\end{tabular}

Only significant $\mathrm{p}$ values are shown; $\mathrm{t}$ tests were used to compare mean 3 months GFR in those with biomarker values below vs. above the median value for each time-point.

\section{Discussion}

The typical distribution of urine $\mathrm{CyC}$ has been described for healthy adults and those with AKI in nontransplant settings $[9,11,12,15]$. The present study is important as the first to demonstrate: (1) the distribution of urine $\mathrm{CyC}$ in recipients immediately following kidney transplantation relative to current definitions of graft function, (2) the utility of peritransplant urine CyC for predicting DGF and (3) the association of peritransplant urine CyC levels with 3-month allograft function.

Urine CyC in Transplant
We noted a stepwise difference in urine $\mathrm{CyC}$ and urine $\mathrm{CyC} /$ urine $\mathrm{Cr}$ levels according to graft function with minimal overlap. Percent change in urine $\mathrm{CyC}$ from $0 \mathrm{~h}$ to each subsequent time-point was also clearly different for those at opposite ends of the spectrum for graft function, but there was substantial overlap between SGF and both DGF and IGF at various time-points. This overlap likely explains the marginal diagnostic performance of urine $\mathrm{CyC}$ for DGF.

Urinary levels of $\mathrm{CyC}$ increase because of its high filtered load with subsequent abnormal reabsorption due to proximal tubular cell dysfunction or injury. Concentra- 
tions return to lower levels as the filtered load and tubular function/reabsorption improves. The acute drop in urine CyC for those with IGF in the current study supports this idea and suggests that despite variable periods of complete ischemia, a subset of kidneys will continue to have well-functioning tubules once reperfusion takes place. Alternatively, release of preformed $\mathrm{CyC}$ into the urine by injured/leaking tubular cells could contribute to urinary CyC levels in AKI.

Importantly, urine $\mathrm{CyC}$ levels here are on a par with those seen in a nontransplant setting of severe acute tubular necrosis. Herget-Rosenthal et al. [15] reported median urine $\mathrm{CyC}$ was $1.7 \mathrm{~g} / \mathrm{mol} \mathrm{Cr}(15 \mathrm{mg} / \mathrm{g}$ in terms of urine $\mathrm{CyC} /$ urine $\mathrm{Cr}$ ) for 26 patients with acute tubular necrosis requiring dialysis support versus $0.1 \mathrm{~g} / \mathrm{mol} \mathrm{Cr}$ $(0.8 \mathrm{mg} / \mathrm{g})$ for 47 patients with acute tubular necrosis who did not require dialysis. These numbers are within $1 \mathrm{SD}$ of mean urine $\mathrm{CyC} / \mathrm{urine} \mathrm{Cr}$ on the second $\mathrm{POD}$ in patients with either DGF or IGF.

We presented both absolute urine $\mathrm{CyC}$ concentrations and urine $\mathrm{CyC} / \mathrm{urine} \mathrm{Cr}$. We and others have previously reported no significant differences after dividing by urine $\mathrm{Cr}[1,16]$, though most of this data remains unpublished. It is important to note there are no clear guidelines for performing this 'adjustment' in the non-steady state. Urine Cr may only modestly 'correct' for urine output/ flow following IRI with the development of isosthenuria, while the amount of any urinary molecule may appear higher after dividing by low urine $\mathrm{Cr}$ due to its impaired excretion $[17,18]$. Thus, dividing by urine $\mathrm{Cr}$ could either hinder or erroneously improve the performance of urinary biomarkers. A timed urine collection for total biomarker excretion may be the most accurate measure, but it is too impractical and error-prone to be used clinically. Large multicenter trials are needed to clarify the role of urine $\mathrm{Cr}$ for biomarker development in various clinical settings, including transplantation.

Several studies have presented data on a variety of novel urinary biomarkers' ability to detect AKI prior to serum Cr [19-23]. Results of the current study build on our earlier data [1]. While we previously reported a lack of utility for kidney injury molecule-1 and good utility for neutrophil gelatinase-associated lipocalin and IL-18, our current findings demonstrate urine $\mathrm{CyC}$, a biomarker of proximal tubular function, has moderate utility for predicting DGF, with the ratio of urine $\mathrm{CyC} / \mathrm{urine} \mathrm{Cr}$ at $6 \mathrm{~h}$ yielding the best AUC.

Given our previous results showing an association between biomarkers of structural kidney injury at the time of transplant and both early and later allograft function, it was interesting to see similar findings with a urine biomarker of proximal tubular function. Our limited sample size did not allow us to combine biomarkers of structural kidney injury (neutrophil gelatinase-associated lipocalin and IL-18) and tubular function $(\mathrm{CyC})$ to determine whether more robust associations with early and later graft function are possible. Evaluating biomarkers of structural injury, which may be too sensitive in the transplant setting, along with biomarkers of tubular function may advance our assessment of meaningful allograft injury in the peritransplant period. Based on the growing body of evidence linking AKI and chronic kidney disease progression [24], understanding the relationship between the degree of structural kidney injury and tubular dysfunction or 'stunning' may be a crucial step toward improving patient outcomes in nephrology.

We have previously described the strengths and limitations of this observational study [1]. Given our fairly small sample size, larger studies should be conducted in the transplant setting to verify our findings. Additional considerations include the inconsistency of protocols for measuring/recording urine output between centers. Future studies should standardize this practice and attempt to measure baseline urine output (residual function) to help clarify its diagnostic/prognostic role and better address the need for urine Cr 'adjustment' and the role that native kidney $\mathrm{Cr}$ excretion plays in this unique setting. The impact of pretransplant dialysis on the filtered load for both CyC and Cr needs further study with serum and urine values obtained just prior to transplant. Furthermore, the effect of baseline GFR, and other factors, on biomarker performance needs clarification in larger multicenter trials in diverse settings of AKI.

In summary, we have shown that urine $\mathrm{CyC}$ is an early and moderately accurate predictor of DGF. Future studies are needed to validate our findings, maximize our understanding of $\mathrm{CyC}$ and other novel biomarkers in this population, and account for additional donor/recipient variables that may impact biomarker values (donor renal function and AKI, immunosupression regimens, etc.). The growing body of literature surrounding biomarkers in transplantation speaks to the need to include them in any future interventional trials for DGF [25]. Urine CyC and other biomarker concentrations in the immediate post-transplant setting may provide valuable insight into the physiology and early diagnosis of IRI, or even describe the 'biomarker fingerprint' of renal recovery following severe AKI. 


\section{Acknowledgments}

We thank Dr. Prasad Devarajan and Dr. Michael Bennett at the Cincinnati Children's Hospital for urine CyC and Cr measurements. We are also indebted to the physicians and staff at each participating transplant center. The views presented here are solely those of the authors and do not necessarily represent the official views of the study sponsors. Dr. Hall was supported by award No. F32DK088395 from the National Institutes of Health (NIH). Dr. Koyner was supported by award No. K23DK81616 from the NIH.
Dr. Parikh was supported by the Clinical and Community Health Grant awarded by The Donaghue Foundation and by award No. UL1RR024139 from the NIH.

\section{Disclosure Statement}

The authors declare no conflicts of interest in the performance and report of this research.

\section{References}

1 Hall IE, Yarlagadda SG, Coca SG, Wang Z, Doshi M, Devarajan P, Han WK, Marcus RJ, Parikh CR: Il-18 and urinary ngal predict dialysis and graft recovery after kidney transplantation. J Am Soc Nephrol 2010;21:189197.

-2 Rodrigo E, Ruiz JC, Pinera C, FernandezFresnedo G, Escallada R, Palomar R, Cotorruelo JG, Zubimendi JA, Martin de Francisco $\mathrm{AL}$, Arias M: Creatinine reduction ratio on post-transplant day two as criterion in defining delayed graft function. Am J Transplant 2004;4:1163-1169.

3 Mikhalski D, Wissing KM, Ghisdal L, Broeders N, Touly M, Hoang AD, Loi P, Mboti F, Donckier V, Vereerstraeten P, Abramowicz D: Cold ischemia is a major determinant of acute rejection and renal graft survival in the modern era of immunosuppression. Transplantation 2008;85:S3-S9.

-4 Daly PJ, Power RE, Healy DA, Hickey DP, Fitzpatrick JM, Watson RW: Delayed graft function: a dilemma in renal transplantation. BJU Int 2005;96:498-501.

-5 Johnston O, O’Kelly P, Spencer S, Donohoe J, Walshe JJ, Little DM, Hickey D, Conlon PJ: Reduced graft function (with or without dialysis) vs. immediate graft function - a comparison of long-term renal allograft survival. Nephrol Dial Transplant 2006;21:22702274.

-6 Humar A, Ramcharan T, Kandaswamy R, Gillingham K, Payne WD, Matas AJ: Risk factors for slow graft function after kidney transplants: a multivariate analysis. Clin Transplant 2002;16:425-429.

-7 Herget-Rosenthal S, Marggraf G, Husing J, Goring F, Pietruck F, Janssen O, Philipp T, Kribben A: Early detection of acute renal failure by serum cystatin C. Kidney Int 2004; 66:1115-1122.

-8 Villa P, Jimenez M, Soriano MC, Manzanares J, Casasnovas P: Serum cystatin C concentration as a marker of acute renal dysfunction in critically ill patients. Crit Care 2005;9:R139-R143, comment 531-532.
-9 Herget-Rosenthal S, Feldkamp T, Volbracht L, Kribben A: Measurement of urinary cystatin $\mathrm{C}$ by particle-enhanced nephelometric immunoassay: precision, interferences, stability and reference range. Ann Clin Biochem 2004;41:111-118.

10 Herget-Rosenthal S, Poppen D, Husing J, Marggraf G, Pietruck F, Jakob H, Philipp T, Kribben A: Prognostic value of tubular proteinuria and enzymuria in nonoliguric acute tubular necrosis. Clin Chem 2004;50:552558.

11 Koyner JL, Bennett MR, Worcester EM, Ma Q, Raman J, Jeevanandam V, Kasza KE, Connor MF, Konczal DJ, Trevino S, Devarajan P, Murray PT: Urinary cystatin $\mathrm{C}$ as an early biomarker of acute kidney injury following adult cardiothoracic surgery. Kidney Int 2008;23:23.

12 Nejat M, Pickering JW, Walker RJ, Westhuyzen J, Shaw GM, Frampton CM, Endre $\mathrm{ZH}$ : Urinary cystatin $\mathrm{C}$ is diagnostic of acute kidney injury and sepsis, and predicts mortality in the intensive care unit. Crit Care 2010;14:R85.

13 Finney H, Newman DJ, Gruber W, Merle P, Price CP: Initial evaluation of cystatin $C$ measurement by particle-enhanced immunonephelometry on the Behring nephelometer systems (BNA, BN II). Clin Chem 1997; 43:1016-1022.

14 Levey AS, Coresh J, Greene T, Stevens LA, Zhang YL, Hendriksen S, Kusek JW, Van Lente F: Using standardized serum creatinine values in the Modification of Diet in Renal Disease study equation for estimating glomerular filtration rate. Ann Intern Med 2006;145:247-254.

15 Herget-Rosenthal S, Poppen D, Husing J, Marggraf G, Pietruck F, Jakob HG, Philipp T, Kribben A: Prognostic value of tubular proteinuria and enzymuria in nonoliguric acute tubular necrosis. Clin Chem 2004;50:552558.

16 Han WK, Waikar SS, Johnson A, Betensky RA, Dent CL, Devarajan P, Bonventre JV: Urinary biomarkers in the early diagnosis of acute kidney injury. Kidney Int 2007;5:5.
17 Waikar SS, Bonventre JV: Creatinine kinetics and the definition of acute kidney injury. J Am Soc Nephrol 2009;20:672-679.

18 Waikar SS, Sabbisetti VS, Bonventre JV: Normalization of urinary biomarkers to creatinine during changes in glomerular filtration rate. Kidney Int 2010;78:486-494.

19 Coca SG, Yalavarthy R, Concato J, Parikh CR: Biomarkers for the diagnosis and risk stratification of acute kidney injury: a systematic review. Kidney Int 2007;19:19.

20 Haase-Fielitz A, Bellomo R, Devarajan P, Story D, Matalanis G, Dragun D, Haase M: Novel and conventional serum biomarkers predicting acute kidney injury in adult cardiac surgery - a prospective cohort study. Crit Care Med 2009;37:553-560.

21 Han WK, Wagener G, Zhu Y, Wang S, Lee HT: Urinary biomarkers in the early detection of acute kidney injury after cardiac surgery. Clin J Am Soc Nephrol 2009;4:873882

22 Mishra J, Dent C, Tarabishi R, Mitsnefes MM, Ma Q, Kelly C, Ruff S, Zahedi K, Shao M, Bean J, Mori K, Barasch J, Devarajan P: Neutrophil gelatinase-associated lipocalin (NGAL) as a biomarker for acute renal injury after cardiac surgery. Lancet 2005;365:12311238.

23 Parikh CR, Jani A, Mishra J, Ma Q, Kelly C, Barasch J, Edelstein CL, Devarajan P: Urine NGAL and IL-18 are predictive biomarkers for delayed graft function following kidney transplantation. Am J Transplant 2006;6: 1639-1645

24 Lo LJ, Go AS, Chertow GM, McCulloch CE, Fan D, Ordonez JD, Hsu CY: Dialysis-requiring acute renal failure increases the risk of progressive chronic kidney disease. Kidney Int 2009;76:893-899.

25 Hall IE, Parikh CR: Human models to evaluate urinary biomarkers of kidney injury. Clin J Am Soc Nephrol 2010;5:2141-2143. 